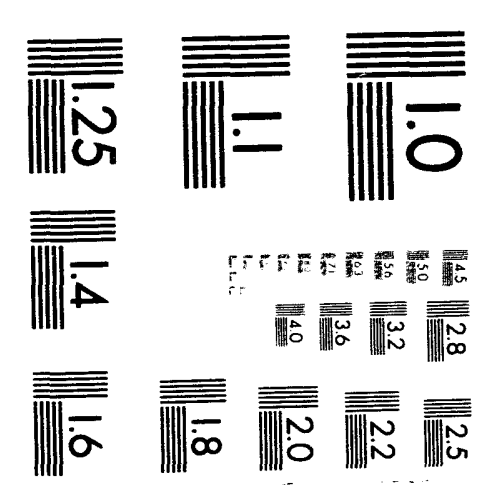



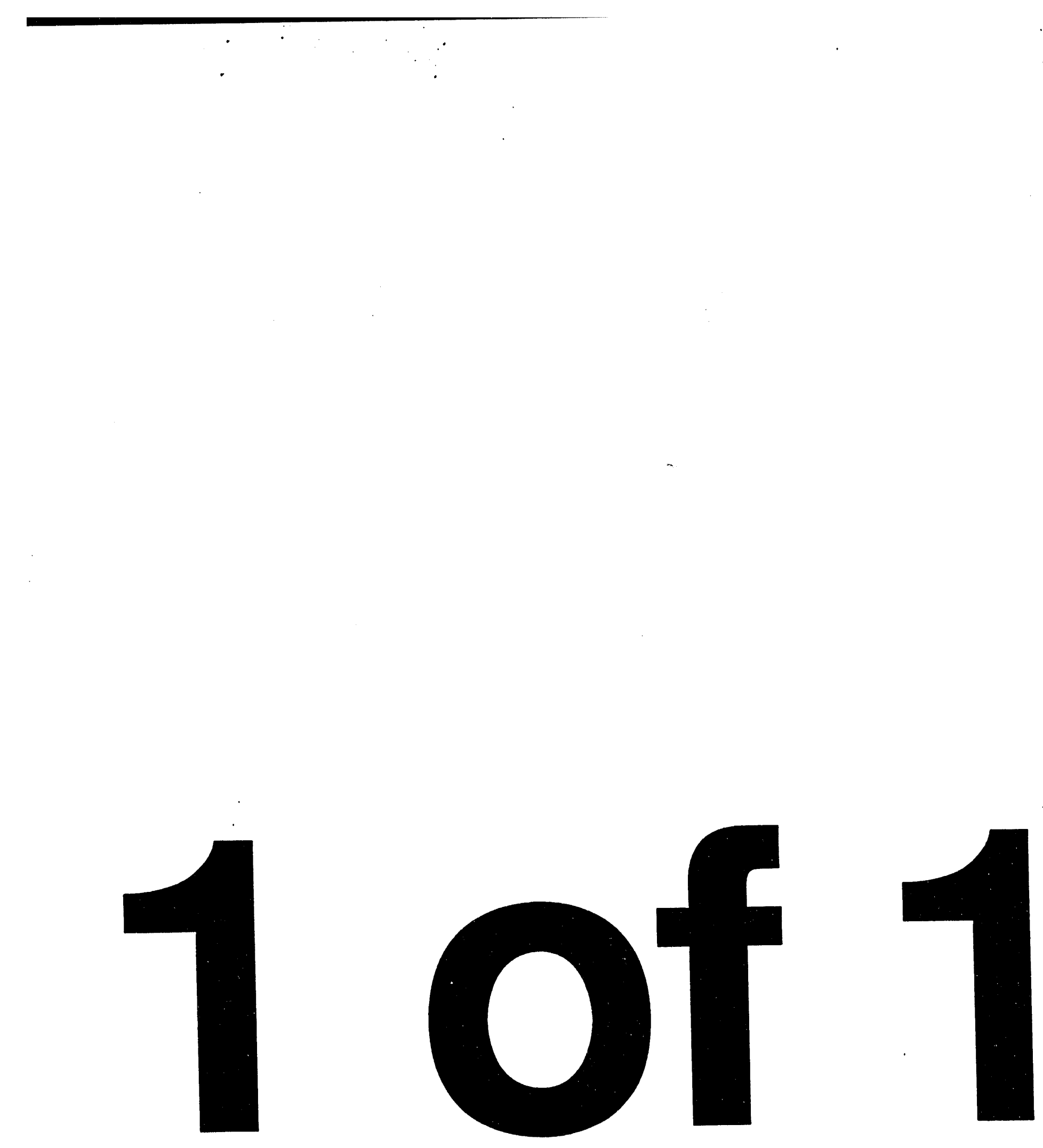
This report was prepared as an account oi work sponsored by an agency of the United States Government. Neither the United States Government nor any agency thereof, nor any of their employees, makes any warranty, express or implied, or assumes any legal liability or responsibility for the accuracy, completeness, or usefulness of any information, apparatus, product, or process disclosed, or represents that its use would not infringe privately owned rights. Reference herein to any specific commercial product, process, or service by trade name, trademark, manufacturer, or otherwise does not necessarily constitute or imply its endorsement, recommendation, or favoring by the United States Government or any agency thereof. The views and opinions of authors expressed herein do not necessarily state or reflect those of the United States Government or any agency thereof.

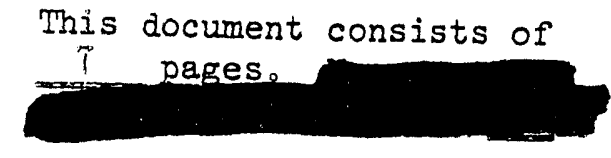

August 27,1963

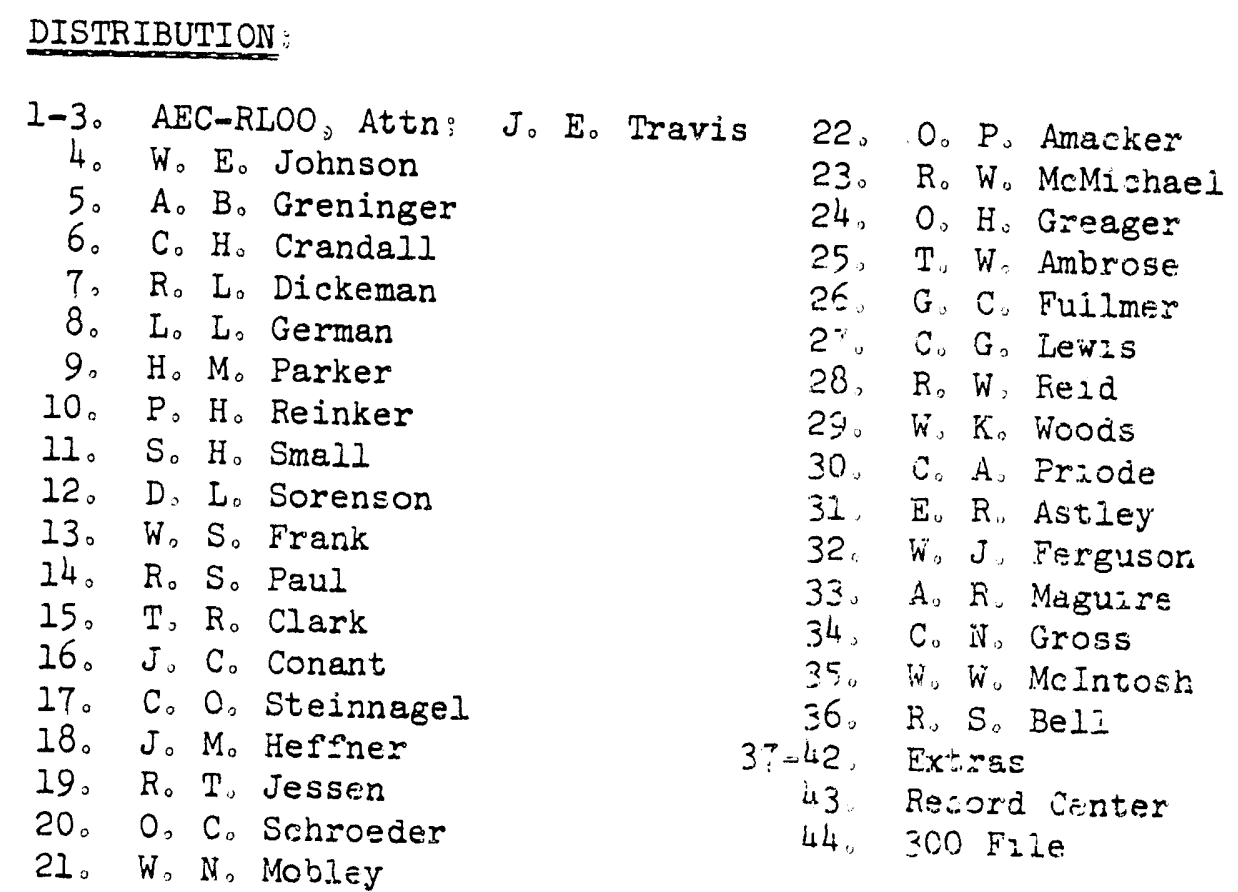

\title{
NUCLEAR SAFETY EXPERIENCE - HANFORD PRODUCTION REACTORS
}

Classification Cancelleo and Changed To

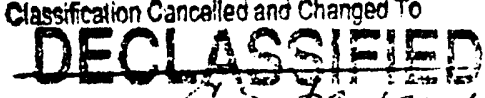

Ey Authority of

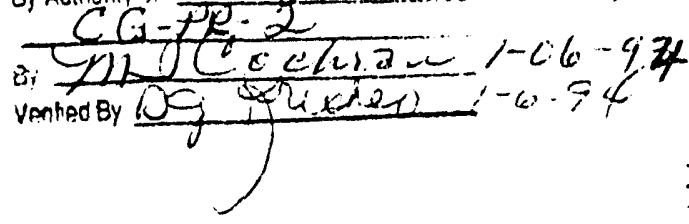

by

O. H. Greager

Research and Engineering Operation Irradiation Processing Department Hanford Atomic Products Operation

\author{
RFC.FIVED \\ MAR 081994 \\ OSTI
}

DECLASSITIED

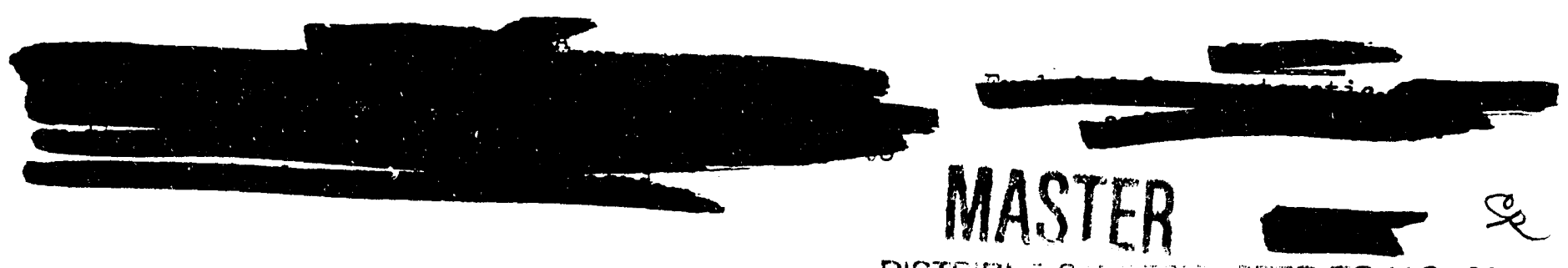

DISTFIBt, 


\section{INTRODUCTION}

Reactor operations at Hanford are to be conducted in the future under a new contract clause on nuclear health and safety, which sets up a form of AEC control somewhat akin to the licensing and regulatory function of the Commission with respect to commercial nuclear plants. As we approach this transition in functional responsibilities ${ }_{\bar{v}}$ it seems appropriate to review the record of more than 100 reactorimears of General Electric oferation at Hanford and to give an accounting of our stewardship in regard to the allaimportant matter of nuclear safety in our production reacter operations.

For the purposes of this reriew the events inince Generai Electric assumed responsibility for plant operations in 1946 may be grouped into three periods. The first of these might be termed "The Early Years" and covers the period 1946 through 1952. During this time three additional reactors were placed on the line to supplement the original three war built reactors. Power levels about doubled over the span, but there were relatively few changes from the original concepts of reactor design and operation, including the approach to reactor safeguards. A second period, 1953 through 1958 , saw substantial advances in technology which led to new resetors, new loadings, and sharpiy increased productive capability. We have identified this period as "The Growing Problem," for it presented many challenges in meeting the need for uncompromising standards of nuclear safety while pioneering new areas of reactor operation. The final period of 1959 to the present sould be called "High Level Operations"; production has been maximized during this period while achieving further progress in refinement of our philosophy and our practices in nuclear safety。

THE EARLY YEARS - 1946 ari 1952

Hanford reactors in 1946 were faced with a serious problem of graphite growth, and it was generally believed that they would have a relatively short period of further useful life. One consequence of this was the decision to place a plant in standby, so as to assure the availability of at least one reactor for the required continuity of operations. On the same basis, the first new reactor to be built in the postwar program was scheduled as a replacement for one of the operating reactors, and accordingly was so located as to use an original water plant after graphite distortion had forced abandonment of the companion reactor facility。

Nuclear safety presented relatively few demands for attention at this time. The original design had been notably conservative, and the margins in nuclear control appeared quite adequate, as to both speed and over-all capacity, for the operating levels then in use. The important matter of cooling water supply also had been well-handled in the original consept, which provided for three independent sources of suppiy. Such a basis remains today the accepted 
standard for our reactor coolant systems. A primary safeguards consideration in those early days was protection against extended loss $0 i^{*}$ coolant flow as a result of boiling within a process tube, such as might occur because of a brief and temporary interruption in the water supply to the tube. The need for such protection was met by the "excess header pressure" requirement。 Under this concept, inlet header pressures were kept high enough, with respect to heatgeneration rates in the fue $i_{;}$to make certain that any steam formed as a result of transient boiling would be swept out of the tube and normal flow restored.

A solution to the graphite growth. problem had been found by the end of 1949. This not only made it unnecessary to make further provisions for replacement reactors, but also permitted a start in the campaign to increase production and decrease costs through raising reactor power levelso Modest increases were made as means were found to deal with corrosion and graphite temperature limits, until at the end of 1952 reactor power levels had been raised to about twice the design rating for the initial reacior plants. At this point the "excess header pressure" limit made furtre: power level increases impractical and it was apparent that another approach to protection against in-tube boiiing would have to be found if continued advances in reactor power levels were to be achieved.

Another problem in nuclear safety which appeared in this early period had to do with the so-called third safety device. As provided originally, this was a solution of boron compound to be released into aluminum thimbles in the reactor as a last-ditch measure, shculd the nuclear reaction for some reason get out of hand and no longer be subject to shutdown by the regular control system. The disadvantages of such a method were clear. In the ilrst place, it could poison the reactor irrevocably should the thimbles leak, even though other circumstances of the incident might have been such as to permit a return to service. And still more importantly: introduction of an aqueous solution into the hot reactor block would be a diolous matter at best, in view of the spattering and stearing effects to be articlpatel.

An answer was found to this problem in the development of a new third safety system using boron steel balls. The ball-3X system, as incorporated in new reactor designs and installed as a modification to the older facilities, provided the required features of assured entry upon demand and recoverability after conclusion of the emergency without the need for thimbles. It is noteworthy that the first major modification project to be carried out at the production reactors had as its objective an improvement in nuclear safety characteristics.

THE GROWING PROBLEM $=1953-1958$

The period 1953=1958 was one of marked increase in production at Hanford。 Two new double-sized reactors were constructed and placed in service at $K$ Area. The six smaller reactors were taken to successively higher power levels as technological progress provided further easing of corrosion and graphite temperature limits; led to better fuel characteristics, and made possible the use of enrichment to secure the added reactivity needed to support the higher power levels. These advances were compounded by a $\$ 37$ milition program of water plant expansion to provide additional coolant, Finally shere was introduced an entirely new fuel design; the internally-and-externally cooled uranium fuel 
element, which was needed to reach operating power levels which would fully exploit the added water plant capability. The overaall result was an improvement in smaller reactor power levels to six times the design rating for an original wartime plant, with a corresponding increment of production from the new large $\mathrm{K}$ plants。

The impact on nuclear safety of the program above had to be evaluated carefully at each step of the way. Much of the development effort was of necessity devoted to investigation of safeguards problems, and making certain that each new advance could be accomplished without compromise of the most rigid standards of reactor safety, Once this had been established to the satisfaction of responsible General Electric personnel, the matter was then reviewed with the Advisory Committee on Reactor Safeguards to obtain their concurrence. This advisory committee to the AEC was formed in the latter part of 1953, to carry on the work of the earlier Reactor Safeguards Committee. As a matter of interest, the RSC had reviewed certain Hanford operations in 1948 and again in 1951; design of the new $K$ reactors had been cleared with this group in early 1953.

As indicated in an earlier section, an "excess header pressure" limit would not have permitted the increases in power level which were achieved in 1953 and later years. In order to attain these increases and still provide protection against the effects of transient boiling in a process tube, it was necessary to devise a new method of protection based upon flow-pressure instrumentation which would cause a shutdown trip before damage could occur; Early results from thermal hydraulic mockup studies provided a basis for "trip-before-boiling" limits. A continuing program of intensive work on the subject made it possible to adopt the progressively less restrictive "trip-before-instability" and "trip-after-instability" limits to tube power without sacrifice of essential protection. As a result of these timely revisions, boiling and instability limits did not become governing during the $1953-1958$ rise of reactor output to higher and higher levels:

In much the same way, the water plant expansion project was subjected to careful safeguards review as an essential step in its execution. New Hazards Summary Reports for the smaller reactors were prepared and presented in detail to the Advisory Committee on Reactor Safeguards at this stage. There was an even more searching examination of the hazards considerations involved in the new internally-and-externally sooled fuel element, as this represented a substantial departure from established heat transfer and hydraulics characteristics of the solid fuel element employed up to this time. The AEC had some reservations regarding possible complications which might arise from use of this new element, and granted approval for the necessary revisions to fuel manufacturing facilities only after full review and endorsement by the ACRS of the new fuel element geometry. It may be noted that it was at about this time (1957) that the Advisory Committee on Reactor Safeguards became a statutory body, as a result of Congressional action apparently related to growing activities in the commercial atomic energy field.

Toward the end of the 1953:1958 period two major issues developed with respect to reactor safeguards at Hanford. The first of these arose from an ACRS recommendation that steps be taken to provade confinement for the fission products

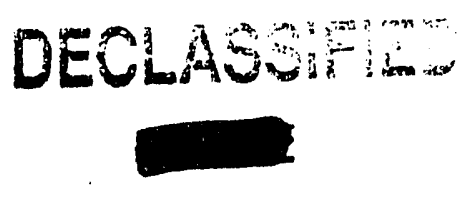


which might be released in the event of a reactor incident. This recommendation was made at the beginning of 1958 and resulted in an AEC decision that there would be no further increases in reactor power levels until this matter had been resolved. Such a limitation remained in effect through the entire year of 1958 . The second issue concerned release of the Wahluke Slope, a matter which had been referred to the ACRS by the Commission at about the same time. These two subjects proved to be somewhat interrelated, and were reviewed jointly at a midyear meeting with the Committee which covered essentially all aspects of the Hanford operation. As a reslitt of the meeting there was transmitted to the AEC 1) ACRS endorsement of Generai Electric"s plans for instailation of confinement provisions at the eight production reactors and 2) a concurrent recommendation for release of all portions of the Wahluke Slope, beyond the primary control zone, for irrigation and development. The conclusions reached by ACRS in regard to nuclear safety at Hanford are worthy of note and the following is quoted from the Committee report

\footnotetext{
"Despite near' $y$ a ten fcid snarease in power level of the Hanford reactors over the Das: ten years the Committee feels that the reactors are safer than ihey ware at the time that the secondary zone of the Wahluke Slope was sstablished。"
}

The ACRS reccmmendation for reiease of the Wahiuke slope was contingent upon a firm decision to prosesd with confinement at the reactors. It also was suggested that in view of this comm:tment it would not be amiss to permit a resumption of power level increases. AEv action to relax the restriction on power level increases took piace earjy in 1950. New limits were set on the basis of subsequent ACRS recommendations; asd were placed at 1800-2000 MW (iater 1900-2100 MW) for the six smaller ractors and $4000 \mathrm{MW}$ for the $\mathrm{K}$ plants. As modified by a further relaxation of ten per cent, approved in 1961 by the AEC, these remain the administrative iims $\because$ or groduction reactor power levels which are in effect today.

HIGH LEVEL OPERATIONS $=19 \div 9-1963$

Current operating power levels, as indicated above, are subject to AEC/ACRS administrative limits. The 1800-2000-4000 MW limits were established after firm commitment to proceed with the confinement project. The further relaxation of about ten per cent became effective when the new confinement systems reached the siuge of beneficial use. It is to be recalled that this system has been designed to provide protection against fission product release from relatively moderate incidents, such as those involving loss of coolant and fuel meltdown in one to several process tubes. It has been recognized by all concerned that the confinement system could be expected to have no substantial effect in reducing the consequences of a major incident which would disable an entire reactor and lead to a catastrophic release of its total fission product burden.

With the largest inweactor inventory of fission products known to exist anywhere in the world, and considering the modest protection afforded by our confinement system, it is apparent trat nuclear safety has had to receive unflagging attention during the present period even though operating levels have remained somewhat stabilized。 Such attention is directed principally to those key aspects of the nuclear control and coolant systems which provide the basic assurance of unfailing protection against, a major reactor incident. 
In the constant review and anaiysis of reactor safety problems it would be helpful to have the benefit of recognized national or industry standards。 It is a hard fact, however, that eyen after two decades of the nuclear age there has been relatively little progress in setting up such standards. It follows then that the proper approach to each safeguards problem becomes a matter of informed judgment on the part of those who are involved. As an aid to making such judgments at Hanford the best thinking of General Electric people responsible for production reactor technology has been formalized in certain criteria covering critical aspects of nuclear control and coolant system reliability. These criteria for "Total Control" "Speed of Control," and "Coolant System Reliability" requirements have been presented to and accepted by both the Advisory Committee on Reactor Safeguards and the General Electric Technological Hazards Council。 Now more than four years old, they have served over this period as the underlying basis for decisions which baye been required on production reactor safety。

In some instances the eriteria haye almost daily application, as in establishing shutdown margins of contro: (in regard to a possible water loss situation), or operating power limits in refezence to available coolant pumping capacity。 Other applications involye the anaiysis of an entire system, as was done in 1959 for the $K$ water plant complex, with the result that a decision was reached to install a new and larger "last-didich" coolant supply. Last-ditch coolant sources at the smaller reacto:s similarly have been the subject of scrutiny. As a consequence, high-tank flow deficiencies have been corrected, and water temperatures in the tanks have been brought inder positive control to assure that cooling would be adequate in case of emergency. The export water system is the ultimate source of last-ditch coolant at the smaller reactors, and this system presently is under test and critical evaluarion for compliance with the applicable criteria。

The prime requisite for safety of the production reactors is a continuous and adequate supply of 100 ing water to tne fuel in the process channels. The normal source of pumping power for this cooling water is electricity from Bonneville Power Administration, with seccndary and last-ditch coolant provided by other means. Loss of BPA power would be the first step in any over-all loss-of-coolant emergency, and sudden loss of this power is an event which enters into the bases for requirements of the "Speed of Control" and "Coolant System Reliability" criteria. By ordinary standards the BPA system generally would be considered as an exceptionally reliable power source, and until last year there had been no occasion to deal with a sudden and complete loss of BPA power to the Hanford plant. In the spring of 1962 , however, the production reactor nuclear safety systems were put to the acid test when there was just such a complete and instantaneous separation from the BPA system on the occasion of a line fault and concurrent equipment failure on the line from the Midway substation. And only a few weeks later, there was another interruption without warning due to failure of a current transformer at Midway.

In each case the Hanford reactor safety systems met this ultimate test in creditable fasion. The reactors shut down without any damaging transients, and secondary coolant systems took over the cooling load promptly and effectively. In no case was the third or lastaditch coolant system called upon to function so as to assure continuity of $c 00$ ing. Such a showing is certainly no basis for 


\section{DECLASSIFIED}

complacency on a matter of such importance as nuclear safety, but there is naturally some gratification that the safeguards features which had been provided were equal to the occasion.

FUTURE OUTLOOK

As of today we are convinced that nuclear safety in the eight production reactors is more assured than was the case in 1946, despite a 35-fold increase in over-all operating power level. This is due to the improvements which have been made both in physical equipment and in operating practices, based upon a much more complete understanding of the nuclear processes involved and their interrelation with the determining factors in reactor safeguards。

Such a background provides the basis that will be needed to move on to new developments required for greater productivity or the manufacture of alternate products in the future. This was demonstrated in the overbore proposal, where it has been clear that the essential features of the suggested reactor changes could be established conservatively with respect to effect on nuclear safety. More recently proposals have been submitted for alternate product loadings which would be of interest in a period of lessened demand for weapons material. While these loadings have not yet been subjected to complete analysis, we anticipate that they can be handled with the same success as the new combination of enriched uranium and target material which has been proved out for regular use in tritium production.

Whatever developments the future may bring, it is our firm resolve that nuclear safety will at all times be the paramount consideration in every phase of reactor design and operation. It is on this basis that we look forward with confidence to such operational requirements as may appear in connection with the Atomic Energy Commission's continuing program at Hanford。

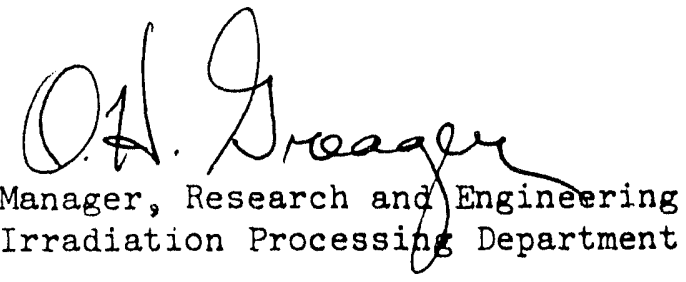

$\mathrm{OH}$ Greager: dg 

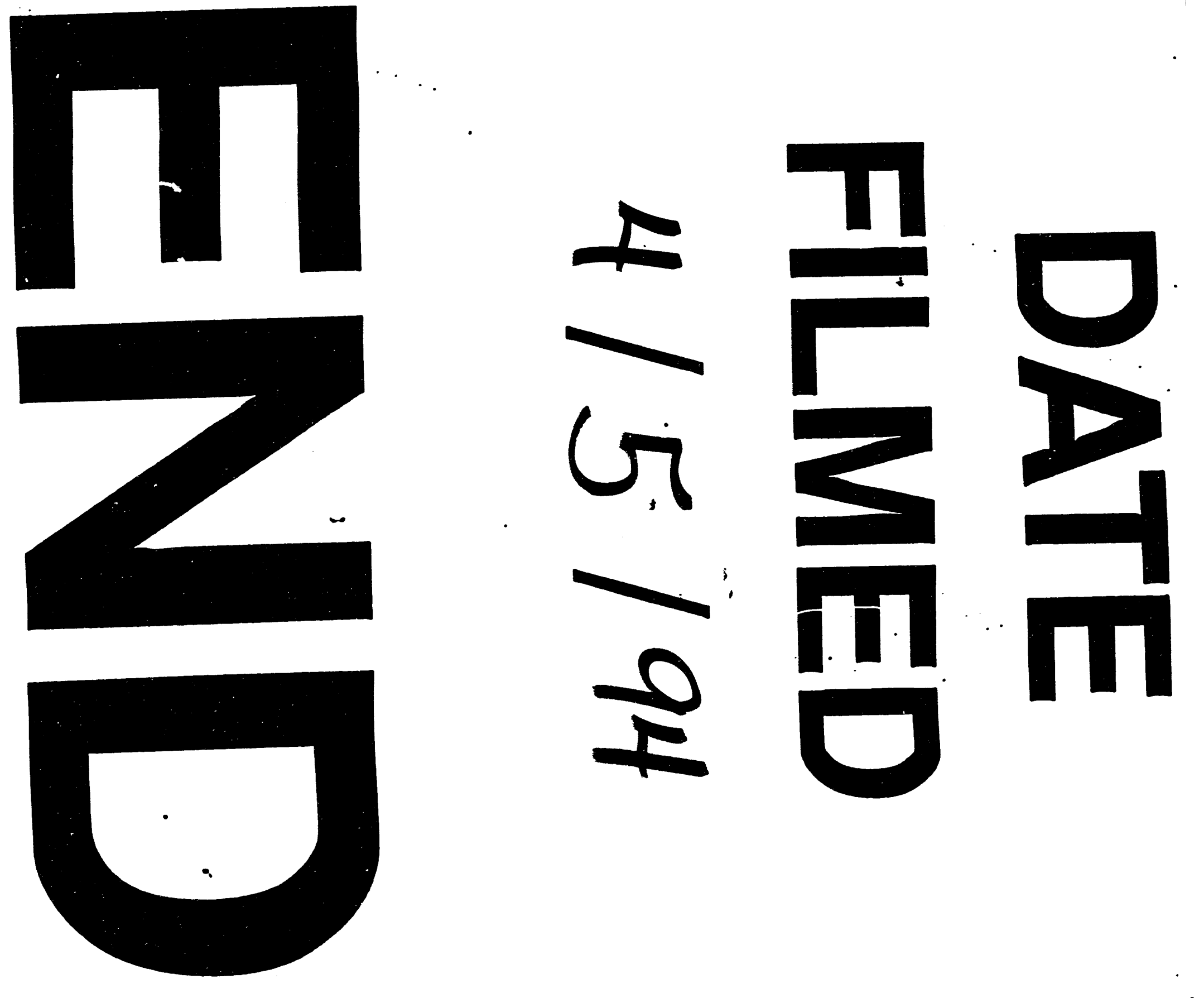
